\title{
Traducciones árabes de la Biblia
}

\author{
Arab Translations of the Bible
}

\author{
Hussein OMAR ZURGHANI \\ Universidad de Trípoli, Libia \\ anaquelestudiosarabes@filol.ucm.es
}

Recibido: mayo 2010

Aceptado: noviembre 2010

\section{RESUMEN}

El artículo trata de la las versiones árabes de la Biblia hechas después de la llegada del Islam. Las traducciones árabes son estudiadas según las lenguas de origen, hebrea, griega, siríaca, que son la base de la lectura ahora vigente, y según la línea samaritana. Enumero los manuscritos árabes que he localizado en las distintas bibliotecas.

Palabras clave: Biblia, traducciones árabes, manuscritos de la Biblia.

\begin{abstract}
The article deals with the Arabic translations from the Bible made after the arrival of Islam. The study is organized according to the three languages, Hebrew, Greek and Syriac, on which the translations are based, and according to the Samarian tradition. I enumerate the Arabic manuscripts that I have located in the various libraries.
\end{abstract}

Key words: Bible, Arabic translations, Biblical manuscripts. 
No hay pruebas sólidas de la existencia de una traducción de la Biblia al árabe en época pre-islamica ${ }^{1}$, pero hay estudiosos que creen en la existencia de una traducción árabe de la Biblia en dicha época².

Después de las conquistas islámicas, a partir del siglo séptimo de la era común (siglo primero de la Hégira), surgió la necesidad de una traducción árabe de la Biblia $^{3}$ cuando un gran número de judíos y cristianos se encontraban bajo gobierno musulmán, y el árabe sustituyó al griego y al arameo como lengua oficial y literaria.

El historiador al-Mas' $\bar{u} d \bar{i}$ (m. 346/957) habla de tres traducciones, una del judío Sa 'īd Ibn Ya'qūb al-Fayyūmī, el famoso Sa'diya, otra del también judío, Abū Katīir Yahyà ibn Zakariyyā at-Tabrānī, y otra la traducción que hizo el nestoriano Hunain Ibn Ishāq (m. 260/873) de la Biblia según la versión griega de los Septuaginta, o de los Setenta, y que al-Mas'ūdī la consideraba como la más perfecta pero, desafortunadamente, esta traducción no nos ha llegado ${ }^{4}$. Al-Mas'ūdī explica que la mayoría de los judíos preferían la traducción de Sa diyya ${ }^{5}$.

Ibn an-Nadīm (m. 438/1047), dice en su Fihrist que Aḥmad Ibn 'Abdallāh Ibn Salām, cliente del califa Hārūn ar-Rašī̄d, tradujo "el Pentateuco, los Evangelios y los libros de los Profetas del hebreo, del griego y del sabeo" al árabe ${ }^{6}$; califica su traducción de literal y no da más datos. Ibn an-Nadīm no habla, en cambio, de la traducción de Hunayn Ibn Isḥāq. De ellas no quedan testimonios.

Vamos, ahora, a mencionar las demás traducciones árabes de la Biblia conocidas:

\section{TRADUCCIONES A PARTIR DEL HEBREO}

Sa'diya Ibn Yūsuf al-Fayyūmī (882-942) ${ }^{7}$ tradujo el Pentateuco del hebreo al árabe. Sa'diyā utilizó la edición hebrea masorética ${ }^{8}$, que era la canónica entre los

${ }^{1}$ E. Britannica, p 764. E. Judaica CD edición.

${ }^{2}$ BLEDDYN J. Roberts, Old testament text and versions, Cardiff, University of Wales Press, 1951, p. 266.

-ADANG, Camilla. Muslim writers on Judaism \& the Hebrew Bible from Ibn Rabban to Ibn Hazm, (E.J. Brill 1996), p. 2.

- TREBOLLE BARRERA, Julio. La Biblia judía y la Biblia cristiana, (Madrid 1993), p. 380.

${ }^{3}$ GEHMAN S. Henry. "The Polyglot Arabic Text of Daniel and its Affinities", Journal of Biblical Literature, 44 (1925), pp 327- 351.

${ }^{4}$ Así lo atestigua GRAF, Georg, Geschichte der christlichen arabischen Literatur, Ciudad del Vaticano 1944-1953, vol. 1, p. 89.

${ }^{5}$ AL-MAS'ŪDĪ, at-Tanbīh wal-išrāff, edición 'Abdallah Isma'īl as-Sāwi (Bagdad: al-Maktaba al'Așriyya, 1357/1938), p. 98.

${ }^{6}$ IBN AN-NADİM, al-Fihrist, ed. Ibrāhīm Ramaḍān, (Beirut: Dar al-Ma'arifa, 1994), p. 37.

${ }^{7}$ Sa'diya Ibn Yūsuf al-Fayyumī, nació en (Abu Swer), en Fayyūm, Egipto y murió en Sura (Mesopotamia). Fue el sabio judío más importante de su época, pues era el Gaón (director) de la famosa escuela de Sura. Cf. H. Malter, Sa 'adja Gaon, His Life and Works, Philadephia 1921.

- Cf. Ibn an-Nadīm Al-Fihrist, pp. 38-39, lo considera el sabío judío más importante y enumera sus obras.

${ }^{8}$ Masora viene del arameo, y significa "recuento" o "enumeración" de los versículos bíblicos. Los autores de la masora iniciaron su actividad en el siglo V d.C., y pertenecían a escuelas de Babilonia y de Palestina. La masora es una serie de anotaciones marginales y finales.

La minuciosa tradición masorética de la Biblia hebrea admite como canónicos menos libros que la Septuaginta que tiene un canon más amplio y más antiguo. Cf. Diccionario enciclopédico de la Biblia, Barcelona: Herder, 1993. 
judíos de su tiempo; de acuerdo con A. Geiger, Sa diya se basaba con frecuencia en la versión babilónica, en casos de divergencia con al versión palestinense ${ }^{9}$. Su traducción es la primera y es la más importante, siendo utilizada entre los $\operatorname{coptos}^{10}$, y por supuesto, entre los judíos que vivían en países musulmanes ${ }^{11}$.

La traducción se conserva en numerosos manuscritos, todos reseñados por Graf $^{12}$, quizá el más conocido sea el ms. de París B.N. árabe $1^{13}$, con una introducción en árabe y latín del copto Faḍlallāh Ibn Tādrus. Ibn Tādrus es el copista principal, y 'Abd Rabbihi bn Muḥammad al-Ansârî, musulmán, el copista del Libro de los Jueces. ${ }^{14}$ Este manuscrito fue la base del texto árabe de la edición políglota, Biblia sacra polyglotta, de Londres, por Brian Walton, en 1657, y de la políglota de París, editada por Guy-Michel Le Jay en $1645^{15}$.

Otros manuscritos son: París, B.N. ar. 3 (es copia de París 1), y París, B.N. ar. 5; Londres, British Museum, ar. christ. 1; Munich, Bib. Estado de Baviera, arab. 233; Vaticano, Borgia ar. 129; Vaticano, Ar. 2 .

Vaticano, ar. $2^{16}$ contiene todo el Pentateuco y no está traducido del griego como afirmaba Assemanus ${ }^{17}$, sino del hebreo. Coincide con el texto del manuscrito de Florencia B. Medicea Laurenziana, or. 21 (112), editado en parte por Kahle ${ }^{18}$, pero presenta variantes respecto del manuscrito de París B.N. ar. 1 (ver infra).

La primera edición de la versión de Sa'diya apareció en la políglota de Constantinopla de 1546, Pentateuchus Hebraeo-Chaldaeo-Persico-Arabicus. Luego, en 1645, el manuscrito de Sa'diya, París B.N. ar. 1, sirvió para la impresión de la Políglota parisina, y a través de ella, para la Políglota londinense de 1657.

En 1893, Joseph Derenbourg publicó el texto de Sa'diyā en caracteres hebreos en Oeuvres complètes de R. Sa diyya Ben Joseph el-Fayyümi ${ }^{19}$. Derenbourg dice en su prólogo que se basó en la edición de Constantinopla, en la Políglota impresa en Londres 1657, y en un manuscrito que su amigo el rabino Nasīm Bajor había traído

\footnotetext{
${ }^{9}$ GEIGER, Abraham. Urschrift und Übersetzungen der Bibel in ihrer Abhängigkeit von der innern Entwickeoung des Judenthums, (Breslau: J. Nainauer, 1857. Reprint Elibron Classics, 2006), p.169.

${ }^{10}$ GRAF, GCAL, p. 101. véase también: Max. L. Margolis y Alexander Marx, Historia del pueblo judio, trad. española (Buenos Aires: editorial Israel, 1945), pp. 270-271.

${ }^{11}$ MARGOLIS, Max L. The story of Bible translations, (Philadelphia: The Jewish publication society of America, 1917; repr. 1948), p. 54.

${ }_{12}^{12}$ GRAF, GCAL, p. 102.

${ }^{13}$ VAJDA, Georges. Catalogue des Manuscrits Arabes, p. 11.

${ }^{14}$ KNUTSSON, Bent. Studies in the text and language of three Syriac-Arabic versions of the Book of Judicum with special reference to the Middle Arabic Elements. Leiden, 1974, p. 27.

${ }_{15}^{15}$ Biblia 1. Hebraica, 2. Samaritana, 3. Chaldaica, 4. Graeca, 5. Syriaca, 6. Latina, 7. Arabica. Quibus textus originales totius Scripturae sacrae, quorum pars in editione Complutensi, deinde in Antverpiensi regiis sumptibus extat, nunc integri, ex manuscriptis toto ferè orbe quaesitis exemplaribus, exhibentur. París: Antonius Vitré, 1645.

${ }^{16}$ Estudiado por Rhode, (nt. 123), pp. 94-97, (referencia en nota 27).

${ }^{17}$ Assemanus Steph. Evodius - Joseph. Sim., Bibliothecae Apostolicae Vaticanae codicum manuscropturm catalogus, vol. IV (Roma, 1831), pt. 2, p. 2

${ }^{18}$ KAHLE, Paul. Die arabischen Bibelübersetzungen: Texte mit Glossar und Literaturübersicht. Leipzig: Hinrichs, 1904, pp. 13-23.

${ }^{19}$ Vol. 1, París, 1893.
} 
del Yemen y que se guardaba en Jerusalén ${ }^{20}$, (no utilizó Florencia, or. 21, Leiden, 377, o Vaticano, ar. 2).

\section{TRADUCCIONES DEL GRIEGO DE LOS LXX AL ÁRABE}

En tiempos de S. Jerónimo (342-420), había tres recensiones de la Septuaginta: la vigente en Alejandría por Hesiquio, la de Constantinopla y Antioquía por S. Luciano, y la de Palestina, basada en la Hexaplar de Orígenes (m. 312) ${ }^{21}$. Las versiones de los Septuaginta llegaron al árabe por diversas vías: 2.1) una directa, como traducción del griego al árabe, aunque es la menos frecuente, 2.2) otra a través del copto, y en concreto, del dialecto buhairí, y 3) otra a través del siríaco, que presenta seis variantes.

2.1. Varios manuscritos dan testimonio de una traducción inmediata, directa, y señalo los manuscritos de El Cairo, Dār al-Kutub, 241; Florencia, B. Medicea Laurenziana or. 12 y Florencia, or. 15; fragmento de Oxford, Bodleian. Arabic Christian, Uri 8 (Huntington 424), Gn. 1: 1-5 y 10 (Fueron publicadas por Rhode en pp. 50*-57*); París, B.N. ar. $15^{22}$.

2.2. Traducciones del griego al copto, y de este al árabe. Las versiones árabes aparecen, al principio, acompañando a las versiones coptas de la Biblia, para facilitar la comprensión, y luego se copian independientemente. No conocemos al traductor o traductores.

- Graf distingue tres recensiones dentro de un primer grupo ${ }^{23}$ :

a) Vaticano, Copt. 1; París B.N. árabe 12 (año 1363, vocalizado), B.N. árabe 16; Oxford, Bodleian, ar. christ. Uri 1 (Hunt. 33) ${ }^{24}$.

b) Vaticano, copt. 2, 3, 4 .

c) París, B.N., copt. 1 (año 1356-1358); Londres, British Museum, copt. 712.

- Graf reúne otros manuscritos en un segundo grupo, indeterminado, de traducciones a partir del copto ${ }^{25}$ : Empieza con el mss. París ar. 12, pero Graf se refiere quizá al ms. París, B.N. ar. 9, del año 1284, sin vocalizar ${ }^{26}$, y añade París B.N. ar. 16, pero solamente sus folios 3-4 (Gn. 1: 1-2). Indica además Vaticano, Borgia, copt. 78; París, BN, copt. 57; Cambridge, Add. 3289; y de nuevo París, B.N. ar. 12, por lo que pienso se equivocó más arriba.

${ }^{20}$ Targum Hamišah Homše Torah be-Lešon 'Aravit le-Rabbenu Sa'diyya Ga'on ben Yusef haFayyumi, (París: Ernest Leroux, 1893), p. 7.

${ }_{21}$ de Lagarde, Paul. prólogo a su edición dela recensión de S. Luciano de Antioquía (m. 312), p.

XIII, citado por Reckendorf, S.Über den Werth der altäthiopischen Pentateuchübersetzung für die

Rekonstruction der Septuaginta. Tesis Universidad de Leipzig, (Giessen, 1886), p. 6.

${ }^{22}$ GRAF, GCAL, p. 103.

${ }^{23}$ GRAF, GCAL, pp. 103-104.

${ }^{24}$ El texto copto de este manuscrito, del Nuevo Testamento, fue editado por David Wilkins como: Novum Testamentum Aegyptium vulgo Copticum ex MSS Bodlejanis descripsit, cum Vaticanis et Parisiensibus contulit, et in Latinum sermonem convertit David Wilkins ... Oxonii (Oxford), e Theatro Sheldoniano Typis et Sumptibus Academiae, 1716.

${ }^{25}$ GRAF, GCAL, p. 104.

${ }^{26}$ VAJDA, Catalogue, p. 16. 
Incluye también: Manchester, Mingana, ar. chist. 4 [7]; Leiden, or. 2366; Londres British Museum, copt. 713; Berlín, ar. 10172, solamente ff. 1v-2v, Gn. 1; El Cairo, 234, ff. 1-10,

El manuscrito de París B.N. ar. 9, terminado en 1284, fue estudiado por Rhode en The Arabic Versions of the Pentateuch in the Church of Egypt ${ }^{27}$ y piensa que es copia de París B.N. ar. 16, el cual habría sido terminado en 1238. Rhode no duda de que es traducción de la Septuaginta, pero le llama la atención que el orden de capítulos y versículos sea el de la biblia hebraica. Reconoce además que los principios de los libros del Éxodo, Levítico, Números, y en especial, Deuteronomio no coinciden con los de la Septuaginta y se pregunta si la comparación con la Hexaplar siríaca (ver p. 53), y su traducción árabe, (manuscritos de Oxford, Bodleian, Laud. Or. 243 y 258) no podría dar la solución.

Este manuscrito, París B.N. ar. 9, lo he consultado en microfilm, y veo que, en efecto, es una traducción hecha sobre la versión de los LXX. El copista es desconocido, pero la copia fue hecha por encargo de un tal Hibat Allāh (f. 328 v) y terminada en el mes de $\operatorname{Rab}^{\top}{ }^{\top}$ II de 683, o sea, 1284. En el manuscrito aparece una anotación de un lector llamado Nașr Ibn Ŷirŷīs (f. 205). Brockelmann recoge un autor llamado Hibat Allāh Nașr ibn Yuhanna Ibn Ŷirŷ̄is, un médico cristiano ${ }^{28}$. En consecuencia este Hibat Allah del encargo de la copia y el Naṣr Ibn Ŷirŷīs de la anotación son la misma persona.

Otra anotación de lectura (f. 272) interesante está hecha por un obispo de Beirut, Yuwakim, con fecha 1534, de modo que la copia circulaba en el aš-Šām.

También he utilizado un microfilm del manuscrito París B.N. ar. 16, que según Rhode es el original del mss. París 9. Se trata de un manuscrito de 237 hojas que, en una antigua numeración, tenía el número $5 \mathrm{~A}$. Fue terminado el viernes 23 de Baramhat del año 954 de los mártires, o sea en 1238, tal como Rhode decía. En una anotación, en latín, al principio, Ascari nos dice que el texto era utilizado entre los coptos y de manera equivocada iguala el año 954 de la era de los mártires con 1217 de la era gregoriana.

Mi impresión es que Rhode no examinó a fondo el manuscrito, porque es bastante diferente del París B.N. ar. 9. Graf distinguía una primera parte del manuscrito, conteniendo Génesis 1: 1-2 del resto. Debo precisar que todo el libro del Génesis es distinto. la traducción de todo el Génesis no coincide con París 9. En cambio, la traducción de París 16 de los otros cuatro libros del Pentateuco coincide, salvo algunos detalles sin importancia, con la de París 9. No se puede decir, por tanto, que París 9 sea copia de París 16, aunque ambos comparten la misma traducción de los cuatro últimos libros del Pentateuco. Ambos manuscritos pertenecen al grupo copto de traducciones, y la clasificación de Graf es aceptable.

${ }^{27}$ RHODE, Joseph. A Study from eighteen Arabic and Copto-Arabic Mss. (IX-XVII) in the National Library at Paris, the Vatican and Bodleian Libraries, and the British Museum. The Catholic University of America, 1921, aquí pp. 70-74.

${ }^{28}$ BROCKELMANN, Carl. GAL, G I, 477, S II, 1029. 
Suhayl Zakkār publicó en Damasco: Dār Kutayba, 2007 un texto del Pentateuco árabe más el libro de Josué bajo el título At-Tawrah. Tarŷama 'arabiyya 'umru-hā aktar min alf 'ām (La Torah. Traducción árabe de hace más de mil años) ${ }^{29}$. S. Zakkār dice que utiliza un manuscrito de 264 folios de medidas 16 x $28 \mathrm{~cm}$, y cada página de 19 líneas. Esta copia se terminó el 24 del mes copto de Bashans de 1052 de los mártires, 1336. S. Zakkār no dice, en ningún momento, dónde se encuentra el manuscrito. De nuevo tenemos un manuscrito que forma parte de la tradición copta.

\section{TRADUCCIONES DEL SIRÍACO AL ÁRABE}

La conquista musulmana se extendió por territorios cristianos de distintas lenguas. Aunque el griego era la lengua administrativa, en Egipto, como hemos visto, se hablaba el copto, y en Iraq y aš-Šām, el siríaco, un dialecto neo-aramaico.

Desde muy antiguo, se cree desde el siglo I de la era cristiana, los habitantes de Mesopotamia y Siria disponían de una versión siríaca de la Biblia. La tradición cristiana atribuye la iniciativa de la traducción a Abgar, rey de Edesa, que habría enviado unos doctores a Palestina para hacer la traducción (Bar Hebraeus, Commentario a Ps. 10) pero ya Teodoro de Mopsuestia (m. 428) reconocía su ignorancia sobre el origen de la traducción siríaca llamda Pešitta, "explicación sencilla" ${ }^{30}$. En lo que hace al Pentateuco, la Pešitta se basa en el texto hebreo; comprende originariamente sólo los escritos del canon masorético, excepto Chr. Ezra, Nehemías y Ester ${ }^{31}$. Pešitta y Vulgata suelen coincidir porque se basan en un texto hebreo próximo, pero además Julio Trebolle señala que la Pešitta "tiene afinidades con el texto de Isaías conocido en Qumrán; ello confiere a esta versión un estimable valor crítico". ${ }^{32}$

Cuando la iglesia siríaca se dividió entre Nestorianos (Este) y Jacobitas (Oeste), se dividió también la transmisión. Filoxeno, obispo de Mopsuestia, en el siglo VI revisó la traducción guiándose por la versión de los Septuaginta. El texto de la Pešitta más utilizado es el impreso en la Poliglota de París, en 1645. En 1914, W.E. Barnes publicó una edición recogiendo la mayoría de manuscritos ${ }^{33} \mathrm{y}$ actualmente, en Leiden se prepara una edición crítica. Hay bastantes manuscritos de la Pešitta que ya Pinkerton, en 1914, analizaba, a destacar los manuscritos del British Museum, de Cambridge, Florencia y el Codex Ambrosianus ${ }^{34}$. Por su parte, Kahle

\footnotetext{
${ }^{29}$ Doy las gracias a Samir Kadduri, Rabat, por llamar mi atención sobre esta publicación. Estoy a la espera de recibir un ejemplar completo del libro.

${ }^{30}$ Cita en P. Kahle, Die Kairoer Genisa (Berlín, 1962), pp. 280.

${ }^{31}$ BAUMSTARK, Anton. Geschichte der syrischen Literatur (Bonn: Markus - Weber, 1922), pp. 18-19.

${ }^{32}$ TREBOLLE, J. La Biblia judía y la Biblia cristiana, (nt. 2), p. 380.

${ }^{33}$ Pentateuchus Syriacae, Londres: Britische und ausländische Bibelgesellschaft, 1914. Pinkerton cita una edición anterior, Lee's Edition, 1823.

${ }^{34}$ PINKERTON, John. "The Origin and Early History of the Syriac Pentateuch", The Journal of Theological Studies (Oxford), 15 (1914) 14-41.
} 
habla de dos grupos; uno el representado por el manuscrito Londres British Museum Add. 14.425, y otro por la mayoría de manuscritos ${ }^{35}$.

Para resumir, digamos que fueron judíos quienes tradujeron el Pentateuco del hebreo al siríaco, y que los cristianos asumieron esta versión, que, sin embargo, fueron retocando. Hacia el siglo V p C esta versión modificada se convirtió en la normalizada, y el Codex Ambrosianus la representa.

En cuanto a las traducciones del siríaco al árabe, Bent Knutsson nos ha proporcionado una relación completa de los manuscritos existentes en diversas bibliotecas que contenienen toda o parte del Antiguo Testamento ${ }^{36}$. Según Graf ${ }^{37}$, hay que hablar de varias líneas de transmisión:

3.1. Melkita, representada por los mss. Vaticano, ar. 468, ff. $1 \mathrm{v}-141 \mathrm{v}$, en primer lugar, y también por S. Petersburgo, Instituto de Estudios Orientales, D 226 ${ }^{38}$; Vaticano, Ar. 465; y Oxford, Bodleian, ar. christ. Uri 9. En el siglo XVI los melkitas compilaron los libros de la Biblia, inclusive el Nuevo Testamento, y el manuscrito de S. Petersburgo D 226 procede del Líbano y es de este período. Del mismo esfuerzo de los melkitas es el mencionado códice Vaticano ar. $468^{39}$, de tres tomos, copiado en 1578/9, que según Knutsson sirvió de base principal a la edición de Propaganda Fide de $1671^{40}$. El ms. Vaticano ar. 467 pertenece también a esta rama melkita. Los códices de S. Petersburgo y Vaticano están relacionados, y son de copia parecida.

3.2. Una segunda línea mezcla la traducción de la Pešitta, que es la base, con otra una versión copta de la Septuaginta. Esta "mejora" se hizo en Egipto y se añadió a la traducción un comentario, de los libros Gén, Éx. y Lev. Los libros no comentados son iguales que Vaticano Ar. 468. Entre los manuscritos reseñados por $\mathrm{Graf}^{41}$, señalo:

a) Vat. ar. 605, 606. Oxford, Bodl. ar. christ. Uri 4 (Pocock. 219), syr. 125. París B.N., ar. 10, ar. 11, ar. 16; los mss. B.N. árabe 10 y 11 son idénticos, y el manuscrito B.N. árabe 11 estuvo a mi disposición. Rhode califica el manuscrito Uri 4 (Pocock. 219) de gran interés, porque suple la versión conservada en la parte más antigua de París B.N. ar. 16. ${ }^{42}$

b) Vat. syr. 216, Oxford, Bodl. syr. 126, 127. c) Vaticano, ar. 33; Vaticano Borgia, ar. 154, París, BN ar. 18, 19. Cairo, 588. d) Cairo, 575. Berlín, sür. 249, Londres, British M, or. 4425, Mingana, syr. 275.

\footnotetext{
${ }^{35}$ KAHLE, Paul. Die Kairoer Genisa, p. 280.

${ }^{36}$ KNUTSSON, B. Studies in the text and language of three Syriac-Arabic versions of the Book of Judicum with special reference to the Middle Arabic Elements. Leiden, 1974.

${ }^{37}$ GRAF, GCAL, p. 104-107.

${ }^{38}$ También Leningrado, Asiatic Museum, 1-3.

${ }^{39}$ RHODE (nt. 27), p. 30, recoge la fecha de 1579, y su carácter melkita.

${ }^{40}$ B. KNUTSSON, Studies, p. 23.

${ }^{41}$ GRAF , GCAL, 106.

${ }^{42}$ RHODE (nt. 27), p. 83.
} 
3.3. Otra línea la sigue una traducción del siríaco solamente y está representada por el manuscrito de la Biblioteca Universitaria de Leiden or. $2365^{43}$. Una parte de París ar. 4 (Números) pertenece a esta línea.

Paul de Lagarde publicó en su libro Materialien zur Kritik und Geschichte des Pentateuch $^{44}$, que he podido cotejar, la traducción árabe del Pentateuco conservada en el manuscrito de Leiden. Lagarde afirmaba que los dos primeros libros del Pentateuco son de Sa'diya, y que los tres últimos, son traducciones del siríaco.

3.4. Otra línea es la traducción directa a partir de Pešitta, y se encuentra en los mss. de París, B.N., syr. 10 (karshuni), pero falta el principio y el final; Manchester, Mingana, ar. Christ.1, incompleto; Berlín, Biblioteca estatal de Prusia, ar. 10172, ff. 3r-46v, correspondientes a Gn 2: 6 y ss.

3.5. Hemos dicho que la iglesia siríaca se dividió en dos, la del este y la del oeste, y con ella se dividió la transmisión de la Pešitta. La Pešitta oriental, de los nestorianos, es la base del ms. de Munich, Biblioteca del Estado de Baviera, ar. $234^{45}$, y de Vaticano, B.A., ar. 525.

3.6. Las secciones antiguas - Gn. 5: 11 - Dt. 32: 42-- del ms. de Oxford, Bodleian, ar. Christ. Uri 8 (Huntington 424), representan otra tradición siríacoárabe, publicadas en parte por Rhode, pp. 57*-63*.

3.7. Roma, Biblioteca Angelica. Copt. 4, ofrece junto a la versión copta básica, otra árabe de origen siríaco, en fragmentos (Gn 1-7, 1: 1-5, 5: 29 - 17: 2).

Orígenes llevó a cabo la primera edición crítica de la Biblia. Orígenes (185-254), uno de los padres de la Iglesia, y apologeta cristiano, había nacido en Alejandría y había estudiado con el neoplatónico Ammonio Saccas (172-242). Orígenes dirigió la escuela catequética de Alejandría en 211-232, y luego emigró a Cesárea, donde fundó otra escuela. Orígenes sabía que el texto griego de la Biblia divergía del texto hebreo, y que éste, como original, tenía más valor que su traducción. Sin embargo, no se daba cuenta de que el texto hebreo también había sufrido una profunda evolución ${ }^{46}$.

La edición de Orígenes contrapone seis versiones de la Biblia, de ahí el nombre Hexaplar $^{47}$. Comprendía el texto hebreo en caracteres hebreos (columna 1), el texto hebreo transcrito en caracteres griegos (columna 2), la traducción griega de Aquila ${ }^{48}$ (ca. 140) a partir de la versión hebrea masorética, pero con apoyo en la Septuaginta (columna 3), la traducción griega de $\operatorname{Simmaco}^{49}$ (hacia 170) a partir del hebreo, pero corrigiendo a la de Aquila (columna 4), la Septuaginta (columna 5), la más

${ }^{43}$ DE GOEJE, M. Catalogus codicum orientalium Bibliothecae Academiae Lugduno-Batavae, (Leiden, 1851), p. 77: ms. MMCCCLXV (Cod. 377 Warner), recoge la fecha de copia de 637/1240, en Mardin.

${ }^{44}$ Leipzig: Teubner, 1867, 2 vols., y se completa con el estudio de J. Caleb Hughes, De Lagardes Ausgabe der Arabischen Übersetungs des Pentateuchs. Cod. Arab. 377 nachgeprüft. Leipzig: Pries, 1914.

${ }^{45}$ GRAF, G. "Die arabischen Pentateuchübersetzung in cod. Monac. 234", en Biblische Zeitschrift 15 (1919-21), pp. 97-115, 193-212, 291-300..

${ }_{46}$ KAHLE, Paul Die Kairoer Genisa, p. 253.

${ }^{47}$ TREBOLLE, p. 326-328.

${ }^{48}$ Prosélito judío y discípulo de Rabí Aquiba. Su traducción es muy literal.

${ }^{49}$ Quizá un samaritano convertido al judaísmo, o un ebionita. A. Geiger lo consideraba un traductor muy "respetuoso" con el original. 
importante, y la de Teodoción ${ }^{50}$, de fines del s. II (columna 6). La edición de Orígenes no se ha conservado íntegra y podemos imaginarnos que la razón es la dificultad de transmitir todas las seis columnas. Al final, se transmitía un texto mixto a base del texto griego de la Septuaginta, y complementos de las demás versiones. Solamente conservamos algunos fragmentos, pero los siríacos lo conocían y este texto mixto fue traducido al siríaco y luego al árabe.

Las versiones siríacas son, pues, importantes. Una primera versión incluía el Pentateuco, los Salmos y Profetas y su revisión produjo la llamada versión "simple", Pešitta, pues se dice "simple" en oposición a la "compuesta", que es la Hexaplar.

El sirio al-Hārit Ibn Sinān Ibn Sinbāt ${ }^{51}$ tradujo el Pentateuco al árabe a partir de la versión siríaca de la Hexaplar de Orígenes. La traducción de Hārit ayuda a completar pasajes perdidos de la Hexaplar. ${ }^{52}$

Su traducción se ha conservado en varios mss.: Escorial ${ }^{53}$, 1857; Vaticano, B.A. Ar. 1; El Cairo, Dār al-Kutub, 255; París, B.N. ar. 13, 14; Oxford, Bodleian, Ar. Christ. Uri 2, y $3^{54}$.

Al-Ḥārit tradujo también, según Abū l-Barakāt Ibn Kabar (m. 1324), los libros de Salomón: Proverbios, Eclesiástico, Sabiduría y Cantar de los Cantares ${ }^{55}$. 'Omar Rida Kaḥāla da otra fecha de la muerte de Abū 1-Barakāt Ibn Kabar: 764/1363 ${ }^{56}$; según Kahāala, este Ibn Kabar era copto, secretario del sultán Baybars y fue autor de una obra polémica contra judíos y musulmanes.

\section{TRADUCCIONES ÁRABES PROCEDENTES DE LOS SAMARITANOS}

Los samaritanos no aceptaban el texto proto-masorético, y tenían su propia edición del Pentateuco, que para ellos era la única Biblia, pues no admiten más libros que los cinco de la Torah.

Había un manuscrito conservado en la sinagoga de Nablus bajo el número (6), que es una copia del año 1204, y es considerado el manuscrito más antiguo actualmente conocido $^{57}$; el manuscrito se encuentra ahora en el British Museum or. 7562. Parece que la traducción es de Abu-l-Hasan aș-Ṣurī que vivía en siglo XI y se cree que es el que hizo la primera traducción árabe de la versión samaritana del Pentateuco ${ }^{58}$. E. Robertson,

\footnotetext{
${ }^{50}$ Parece que era un prosélito judío de Éfeso. Se habla de un "texto teodociónico" anterior a Teodoción, del siglo I d.C.

${ }^{51}$ Procedente de Harrān, vivía entre los siglos IX y X, perteneciente a la comunidad melkita. Hizo la traducción del Pentateuco en base a la versión de los Setenta: véase Joseph.Nasrallah, Histoire du mouvement littéraire dans l'église melchite du $V^{e}$ au XX $X^{e}$ siècle, (éditions Peeters 1981). vol. II, tome 2, p. 187.

${ }^{52}$ GRAF, GCAL, p. 130.

${ }^{53}$ DERENBOURG, Hartwig. Les manuscrits arabes de l'Escorial. Décrits d'aprés les notes de Harwitg Derenbourg; revues et mises à jour par E. Lévi-Provençal. Paris: Librairie Orientaliste Paul Geuthner, 1928.

${ }^{54}$ GRAF, GCAL, p. 107.

${ }^{55}$ GRAF, GCAL, vol. 1, p. 129

${ }^{56}$ Kahāla, O.R. Mu 'ýam al-Mu'allifin (Damasco: Maktaba al-'Arabiyya, 15 vols.), vol. 3 (1957), p. 41.

${ }^{57}$ Šahada, Hasīb. Ha-Targūm ha- 'Aravī li Nosah ha-Torah Šel ha-Šomronìm, tesis doctoral para la universidad Hebraica de Jerusalén, 1977, p 4.

${ }^{58}$ Encyclopedia. Judaica, CD edition.
} 
citado por B. Roberts ${ }^{59}$, dice que lo que hizo Abu-1-Hasan fue aprovechar la traducción de Sa‘diya. Abu-1-Hasan vivía unos 80-100 años después de Sa'diya y a pesar de que solamente hizo una adaptación al Pentateuco samaritano, fue conocido como su traductor. Roberts añade que Abū Sa'īd, conocido también como Abu-l-Barakāt, en cambio, sí hizo, en el siglo XIII, una nueva traducción a partir del texto hebreo con la ayuda del targum samaritano, y posiblemente la pešitta, y ésta es la versión árabe reconocida y usada por los samaritanos ${ }^{60}$.

A. Silvestre de Sacy fue el primero en estudiar las versiones de los samaritanos y estableció que dicho Abū Sa ‘īd fue uno de los traductores, en $1070^{61}$. Abū Sa ‘̄id, en el prólogo, se lamentaba de que los samaritanos utilizaban la traducción de $\mathrm{Sa}$ 'diya que él consideraba deficiente. En cierta manera, $\mathrm{Abū} \mathrm{Sa}$ ‘īd le daba la razón a Roberts.

${ }^{59}$ ROBERTS, B.J. Old testament text and versions, p. 196.

${ }^{60}$ ROBERTS, B.J. p. 196.

- KAHLE, P. Die arabischen Bibelübersetzungen, pp. 11-13.

${ }_{61}$ "Mémoire sur la version arabe ds livres de Moïse à l'usage des Samaritains ", Mémoires de l'Académie des Inscriptions, París, 1808, citada por Allgermissen. 